\title{
Teoria do conhecimento e epistemologia na pesquisa em educação física
}

Gabriel Pereira Paes Neto

Mestre pela UFPA

Ney Ferreira França

Mestre pela UFPA

Renan Santos Furtado

Acadêmico da UFPA

\section{Resumo}

Trata-se de pesquisa bibliográfica na qual analisamos a pesquisa na educação física em torno da perspectiva de reaproximação da epistemologia com a teoria do conhecimento. As pesquisas devem pressupor a práxis e a dialética, sendo que à luz destas devem abordar os problemas do conhecimento, da história e da realidade, também o materialismo histórico dialético enquanto epistemologia e o socialismo enquanto projeto histórico. A pesquisa em educação física deve reverter o seu circuito de conhecimento, superando os modelos hegemônicos, avançar na passagem das questões instrumentais, técnicas e metodológicas para as teóricas e epistemológicas.

Palavras-chave: Teoria do Conhecimento; Epistemologia; Educação Física.

\begin{abstract}
This is literature in which we analyze the research in physical education around the rapprochement perspective of epistemology with the theory of knowledge. Research should assume praxis and dialectics, and the light of these should address the problems of knowledge, history and reality, also the historical dialectic materialism as epistemology and socialism as a historical project. Research in physical education should reverse their circuit knowledge, overcoming the hegemonic models, advance the passage of instrumental, technical and methodological for the theoretical and epistemological.
\end{abstract}

Keywords: Theory of Knowledge; epistemology; Physical education.

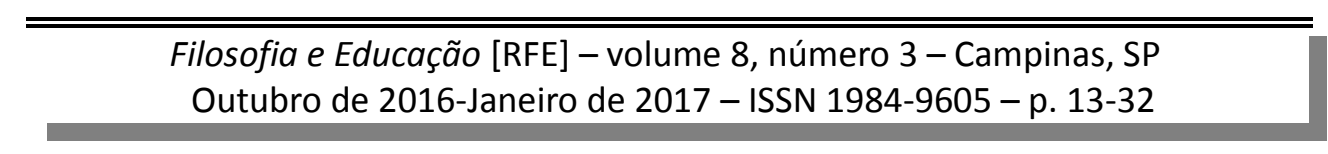




\section{Introdução}

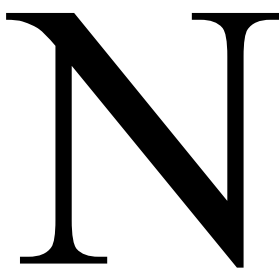

ossa pesquisa foi desenvolvida através de estudos da linha de pesquisa em produção do conhecimento da LEPEL/PARÁ. Trata-se de pesquisa bibliográfica na qual tivemos o objetivo de tratar de questões referentes à epistemologia e à pesquisa na educação física (EF) a partir da perspectiva de reaproximação da epistemologia com a teoria do conhecimento, a partir do materialismo histórico dialético (MHD).

Pressupondo a décima primeira Tese de Feuerbach: "Os filósofos limitaram-se a interpretar o mundo de distintos modos; o que importa é transformá-lo" (Marx e Engels,2007: 535), expressa a concepção de práxis. De acordo com Marx e Engels (2007), a concepção da história consiste em tratar da história real, explicar as formações ideais a partir da práxis material, pressupondo a revolução como a força motriz da história. Assim, é preciso fazer a conexão entre a filosofia e realidade, pois os pressupostos são reais, são indivíduos reais, sua ação e suas condições materiais de vida. Para Marx a produção de ideias está imediatamente entrelaçada com a atividade material, trata-se de considerar que a vida é que determina a consciência.

Sobre a pesquisa bibliográfica, de acordo com Gil (2002) e Minayo (2010) trata-se da recorrente leitura, abstração, análises sistemáticas, fichamentos. Portanto, a pesquisa bibliográfica desenvolve-se ao longo de uma série de etapas, desde a aproximação com o objeto, problematização, até a análise dos dados. Considerando que o processo de abstração é indispensável para o conhecimento e construção teórica, pois para Netto (2011) o pensamento localiza, detecta, interpreta esses processos, os quais são conectados a outros processos.

Optou-se pelo materialismo histórico dialético como a lente que ajuda a olhar o objeto desta pesquisa, para o processo analítico necessário para a 
análise do real, do concreto pensado do objeto, o qual se encontra inserido no seio das contradições e determinações da sociedade do capital.

Nossa pesquisa também se caracteriza como epistemológica, pois seria um estudo de segunda ordem, a razão (logos) do conhecimento (episteme), portanto, um estudo da natureza, da justificativa e dos limites da ciência. $\mathrm{Na}$ medida em que a pesquisa reata os vínculos entre a teoria do conhecimento e a epistemologia, mais especificamente com o MHD, adquire expressão e decorrências materiais, práticas e transformadoras, sobretudo a partir da relação entre dialética, totalidade e práxis.

A partir deste movimento na pesquisa, estas podem decorrer do real, partindo e voltando ao real, sendo que na EF não seria diferente. Assim, de acordo com Gamboa (2010) a EF encontra-se num patamar de desenvolvimento da definição de seus campos epistemológicos no quadro geral das ciências. Todavia, tratamos de questões sobre a natureza da EF, analisando a possibilidade de superação desse quadro, o qual estaria na reversão do circuito do conhecimento, com base no MHD e no paradigma da cultura corporal.

Tivemos como problema de pesquisa: quais as possibilidades da pesquisa na $\mathrm{EF}$ a partir da perspectiva de reaproximação da epistemologia com a teoria do conhecimento com base no materialismo histórico dialético? Contudo, ressaltamos que a pesquisa epistemológica, além de articular as técnicas, os métodos e as teorias numa determinada concepção de ciência, supõem concepções filosóficas relacionadas com as teorias de conhecimento que dão apoio aos processos científicos.

\section{Teoria do conhecimento e epistemologia}

Considerando que a teoria seria uma explicação elaborada, de acordo com Taffarel (2010), a partir de uma dada lógica de apreensão, compreensão e ação dialética com o real. Portanto, podemos pensar a teoria da educação 
física, as explicações a respeito da produção do conhecimento científico na $\mathrm{EF}$, segundo determinada lógica de pensar e agir no real.

Ainda de acordo com Taffarel (2010), é preciso pesquisar partindo de análises e nexos intelectivos entre a modernidade, o capital, a exploração, estranhamento e alienação do trabalho, entre outros elementos. Assim, a ciência pode retomar um papel importante na práxis e no projeto histórico de superação do modo de produção capitalista. De acordo com a autora esta discussão é fundamental para a compreensão da contradição alienação $\mathrm{x}$ emancipação humana no bojo das pesquisas em EF.

Considerando o exposto acima, a pesquisa epistemológica seria um estudo de segunda ordem, portanto, um estudo da natureza, da justificativa e dos limites da ciência, perpassando em possibilidades de fontes, da essência e dos critérios de validade de um conhecimento. Gamboa (2010) entende que a epistemologia, como campo de conhecimento não normativo, não tem normas nem limites rígidos, sobretudo se considerarmos a possibilidade de expandir a epistemologia à teoria do conhecimento. A partir de nossa opção pelo MHD, então, é necessário expandir a reflexão sobre a obra humana, sobre a obra científica, ampliar as possibilidades de transformar a própria ciência, o modo de produção capitalista e a sociabilidade humana.

De acordo com Gamboa (2010), diante da reaproximação entre teoria do conhecimento e teoria do conhecimento científico seria fundamental optar pelo MHD, pois nesta perspectiva não há a divisão entre gnosiologia e epistemologia, a teoria do conhecimento torna-se teoria da sociedade, da sua evolução, da educação, etc. uma teoria dialética da sociedade, uma epistemologia aberta e transformadora. Para o autor, o surgimento do interesse pelas matrizes teóricas e as concepções de ciência que orientam a produção do conhecimento, indica o avanço na passagem das questões instrumentais, técnicas e metodológicas para as teóricas e epistemológicas.

Filosofia e Educação [RFE] - volume 8, número 3 - Campinas, SP

Outubro de 2016-Janeiro de 2017 - ISSN 1984-9605 - p. 13-32 
Nesse bojo é pertinente o constante diálogo da EF com as disciplinas fundadas nas ciências naturais, nas ciências sociais e humanas.

Sobre a educação física, de acordo com Gamboa (2010), a área encontra-se num patamar de desenvolvimento da definição de seus campos epistemológicos no quadro geral das ciências. $\mathrm{O}$ autor ressalta que a área não precisam repetir os caminhos de outros já consolidados para conseguir a definição de seu estatuto epistemológico. Por um lado, a EF tem sido um campo de passagem nas pesquisas, por outro lado, a superação desse quadro está na reversão do circuito do conhecimento, tomando como ponto de partida e de chegada a EF. Sendo assim, o circuito das pesquisas passariam pelas teorias, as sistematizações, isto é, voltando suas contribuições para a explicação e compreensão da ação e práticas dos movimentos próprios dos fenômenos.

Gamboa (2010) defende que o objeto de pesquisa da EF é a ação, a prática, a práxis, tendo como ponto de partida e de chegada a cultura corporal. Nesse sentido o autor defende que as concepções de homem são categorias e pressupostos de caráter ontológico, das quais se desdobram outros conceitos que constituem o horizonte interpretativo. Para isso a abordagem crítica dialética tem como matriz epistemológica o MHD, pressupondo a concepção de homem histórica de sujeito social transformador da natureza e da sua própria natureza, tencionados pelos interesses emancipatórios da luta por maiores níveis de vida.

De acordo com Gamboa (2010), os instrumentos oferecidos pela dialética parecem ser ricos em desdobramentos, pressupondo a articulação prática-teoria-prática, oferece um maior potencial de compreensão. Ainda de acordo com o autor é à luz da práxis que se devem abordar os problemas do conhecimento, da história, da sociedade e da própria realidade.

Gamboa (2010) menciona que a dialética, na sua fase operacional é um método de compreensão da realidade que não se esgota na interpretação 
dessa realidade. Para o autor seria preciso a radicalização na dialética teoriaprática. Portanto, a EF deve se assumir como ciências da práxis. Já sobre a dimensão da historicidade, o autor parte do pressuposto de que em toda pesquisa científica sempre se trabalha com um a priori, com o tempo, e com uma maneira de apreensão deste. Assim, toda pesquisa que aborda fundamentalmente fenômenos histórico-sociais, trabalha com atributos intrínsecos à existência do real, tais como, o tempo e o espaço.

Considerando o exposto, de acordo com Gamboa (2010), acredita-se que os fenômenos sociais devem ser abordados considerando-se sua historicidade, pois se trata de um atributo inerente à existência do real. Assim, a concepção diacrônica de história é pertinente nos enfoques dialéticos, pois a história refere-se à compreensão da dinâmica interna dos fenômenos que se torna foco prioritário das buscas. Nesse sentido, a explicação e a compreensão dos fenômenos estão na própria história do fenômeno e a sua historicidade passa a ser preocupação prioritária.

No contexto da produção científica, em EF vem crescendo o interesse pela análise filosófica e os estudos epistemológicos, todavia, preservou-se na área o dualismo entre a abordagem quantitativa e a qualitativa, o que limita a riqueza da descoberta do conhecimento. De acordo com Gamboa (2010), as técnicas devem ser compreendidas na sua relação com os outros níveis de articulação da pesquisa científica, devem estar articuladas com os métodos, os referenciais teóricos, as abordagens epistemológicas e os pressupostos filosóficos nos quais se fundamentam as pesquisas. Os paradigmas epistemológicos supõem concepções filosóficas relacionadas com as teorias de conhecimento que dão apoio aos processos científicos e supõem também concepções do real ou visões de mundo que de forma implícita sustentam toda relação cognitiva. Esses níveis de articulação se explicitam assim.

Filosofia e Educação [RFE] - volume 8, número 3 - Campinas, SP

Outubro de 2016-Janeiro de 2017 - ISSN 1984-9605 - p. 13-32 
Técnico-instrumental, que se refere aos processos de delimitação de fontes, coleta, registro, organização, sistematização e tratamento de dados e informações; Metodológico, que se refere aos passos e procedimentos e maneiras de abordar e tratar o objeto investigado; Teóricos, que se referem à seleção ou escolha de fenômenos educativos ou sociais privilegiados como focos de observação, núcleos conceituais básicos, organização de categorias explicativas, críticas a outras teorias, autores cultivados, etc.; Epistemológicos, relativos aos critérios de validez científica, concepções de ciência, de prova e de causalidade. (p.104 e 105).

Ainda de acordo com Gamboa (2010), a partir desses níveis de articulação é possível reconstituir os seguintes pressupostos:

Gnosiológicos que se referem às maneiras de definir, delimitar e tratar o objeto; maneiras de relacionar o objeto e o sujeito e que fazem referências aos critérios de objetividade e de subjetividade ou a maneira da "construção do objeto"; Ontológicos que se referem a categorias gerais implícitas em toda produção sistemática do conhecimento tais como concepções de homem, corpo, sociedade, tempo, educação e realidade e que se articulam na visão do mundo do pesquisador. (p.104). 
Portanto, de acordo com Gamboa (2010), a articulação entre os vários níveis supõe um processo compreensivo progressivo. Assim, trata-se do processo da pesquisa que qualifica as técnicas e os instrumentos necessários para a elaboração do conhecimento. As opções técnicas dependem dos caminhos a serem percorridos e dos procedimentos a serem desenvolvidos. Nesse sentido, as técnicas só têm sentido dentro das abordagens metodológicas.

De acordo com Albuquerque e Taffarel (2010), enfatizamos que este trabalho de pesquisa está "sendo travado no momento em que a humanidade se depara com mais uma das profundas crises do capital, o qual busca se recompor, e obter cada vez mais, exorbitantes taxas de lucro". Ainda, marcado pela "propriedade privada dos meios de produção da vida, e pelo alienante trabalho assalariado" (p.9).

\section{O MDH e a pesquisa em educação física}

A concepção materialista dialética da história é extremamente atual, todavia, de acordo com Albuquerque e Taffarel (2010), prevalecem hegemonicamente no Brasil teorias reformistas e antirrevolucionárias, mesmo que existam reações na luta concreta, onde se buscam construir e erguer outros pilares para a produção do conhecimento científico e para a escolarização.

Segundo Sá, Silva e Santos (2013), é necessário considerar a dialética como método de raciocínio teórico-científico, portanto, “considerar que nas leis e categorias próprias da dialética é possível refletir as leis mais gerais da realidade objetiva das pesquisas em seu conjunto" (p.266). Já de acordo com Albuquerque e Taffarel (2010), são necessárias novas sínteses em patamares teórico-práticos mais elevados, portanto a defesa do materialismo histórico dialético enquanto epistemologia e o socialismo enquanto projeto histórico:

Filosofia e Educação [RFE] - volume 8, número 3 - Campinas, SP

Outubro de 2016-Janeiro de 2017 - ISSN 1984-9605 - p. 13-32 
É necessário avançar, reagir, resistir, através de rupturas e saltos qualitativos, para novas sínteses em patamares teórico-práticos mais elevados, superando os desvios teóricos, rompendo ilusões, lutando contra o fetichismo, o irracionalismo e o idealismo, buscando a referência clássica marxista. Ventos de esquerda ainda sopram na América Latina, contraditoriamente, e o marxismo, enquanto filosofia, o materialismo histórico dialético enquanto epistemologia e, o socialismo enquanto projeto histórico, eles estão recolocados mais fortes do que nunca, pela sua aderência ao real, como referência para tratarmos da produção do conhecimento científico e das políticas públicas na perspectiva do projeto histórico para além do capital. (p.12).

De acordo com Marx e Engels (2007), para "o materialista prático trata-se de revolucionar o mundo" (p.29). Assim, é preciso conceber a história como desenvolvimento do processo real de produção a partir da produção material da vida, ressaltando que o primeiro ato histórico "é a produção da vida material" (p.33), portanto, "a primeira coisa a fazer em qualquer concepção histórica é observar esse fato fundamental" (p.33) em toda sua significação e em todo seu alcance. Portanto, para Marx é necessário permanecer sobre o solo da história real, entendendo a revolução como a força motriz da história e lembrando que as ideias dominantes são as relações materiais dominantes apreendidas como ideias.

A perda da objetivação e subjetivação na vida diante da exploração da força de trabalho causa o estranhamento do ser consigo, com o outro e com 
a natureza. De acordo com Marx e Engels (2007), ocorre a mistificação do indivíduo e das forças produtivas, as quais se apresentam como independentes e separadas dos indivíduos, em seguida os indivíduos existem em oposição uns aos outros. Para Marx, é necessária que haja a compreensão desse processo por uma filosofia que garanta a conexão entre a filosofia e a realidade, partindo de pressupostos reais, das condições materiais, pois “os pressupostos são reais, são indivíduos reais, sua ação e suas condições materiais de vida, constatáveis por via empírica" (MARX e ENGELS, 2007. P.87).

Marx e Engels (2007) nos dizem que há conexões entre a estrutura social e política com a produção, portanto "os indivíduos determinados contraem entre si estas relações sociais e políticas determinadas, ainda que isso determine a formação dos sujeitos, pois "a produção de ideias está imediatamente entrelaçada com a atividade material com a linguagem da vida real" (p.93). Portanto, para Marx a análise se eleva da "terra ao céu", pois é a vida que determina a consciência, os pressupostos são materiais, são os homens em seu processo de desenvolvimento real, sendo que tal processo é empiricamente observável, e ainda, sob determinadas condições de tempo, espaço, conjuntura.

Sobre a questão da percepção de um fato, de acordo com Karl Marx e Friedrich Engels (2007), a aparência é o ponto de partida, mas ela também esconde, mistifica. Assim, conhecer é negar a aparência, ir além da empiria. Para os autores, o conhecimento empírico ainda não se constitui como teoria, pois seria um indicador dos processos e é um passo do conhecimento teórico. No caminhar metodológico, cabe à razão identificar esses processos, ou seja, a razão no movimento de abstração deve ir além das factualidades para que ocorra a identificação dos processos que as implicam.

A opção pelo MHD, como a lente que ajuda a olhar o fenômeno, oferece um meio para se analisar o mesmo. O pesquisador parte da 
intencionalidade de analisar as categorias inerentes ao fenômeno para buscar a gênese, a estrutura, o desenvolvimento, as contradições inerentes ao mesmo, buscando historicizar, uma vez que a intencionalidade se permeia no sentido da elaboração de novas sínteses, proposições e da realização da práxis social. De acordo com Albuquerque e Taffarel (2010) é necessário propor: "o materialismo histórico dialético enquanto possibilidade epistemológica, o marxismo como filosofia e o comunismo como projeto histórico, enquanto base e fundamentação de propostas educacionais e de proposição pedagógica" (p.45).

Sobre o processo de pesquisa de Marx, segundo Netto (2011), sabe-se que a realidade é complexa por ser a síntese de muitas determinações, o conhecimento teórico é o conhecimento do concreto que constitui a realidade, mas que não se oferece imediatamente ao pensamento. Assim, é fundamental a análise das relações entre os processos inerentes ao objeto, pela análise categorial, ou seja, sua totalidade, contradições e das mediações com a totalidade concreta. Inicialmente o pesquisador procura situar a problemática de estudo, assim como os passos e procedimentos da pesquisa, além de relacionar com os fundamentos ontológicos e metodológicos.

Sabe-se que são três as categorias nucleares que compõem o processo metodológico da pesquisa de Marx, ou seja, que fundam o elenco categorial nuclear metodológico da pesquisa Marxiana, sendo elas: totalidade, mediação e a contradição. Em linhas gerais, a concepção de realidade de Marx se insere na estrutura da totalidade (a qual seria um complexo de complexos), porém, de acordo com Cury (2000), é importante mencionar que a totalidade pode estar vinculada à categoria contradição, pois os sistemas de contradições dinamizam as totalidades e, ainda, a totalidade e a contradição só tem sentido junto com a categoria mediação.

A realidade para Marx, de acordo com Netto (2011), é dinâmica e processual, ou seja, perpassa pelas contradições e antagonismos que 
constituem a realidade, sendo que, a realidade sócio-histórica constitui uma totalidade. Portanto, a sociedade constitui uma totalidade e é o sistema que vincula os indivíduos, que se vinculam à família, que, por sua vez, compõem classes sociais, frações de classe, que compõe sociedades nacionais, etc. Há, portanto, uma complexidade da estrutura.

Ainda de acordo com o autor, a sociedade é um sistema articulado, pois as totalidades são articuladas. É importante mencionar que Marx não reduz a totalidade complexa à econômica. As totalidades são articuladas, todavia para o autor, há aquela que constitui o momento da determinação, há entre elas momentos de subordinação e coordenação. Nessa linha de pensamento, o objeto é uma totalidade que, por sua vez, é outra totalidade que se insere em outras. Estas totalidades têm mediações entre elas.

Considerando que a matéria antecede ao pensamento, então, são as ações que determinam as ideias. Então, esta filosofia que parte dessa premissa é a filosofia da práxis. De acordo com Vázquez (2007), esta filosofia é o marxismo. Entendida dessa forma, a práxis ocupa o lugar central da filosofia como elemento do processo de sua transformação. De acordo com Vázquez, para chegarmos a uma verdadeira concepção da práxis, temos que passar necessariamente, do ponto de vista histórico filosófico, por sua concepção idealista, para então compreendê-la e superála. Para Vásquez, o idealismo filosófico não é superado, portanto, com qualquer filosofia, mas sim com aquela que por revelar teoricamente o que é a práxis, a que aponta para as condições que tornam possível a transição da teoria da prática, e assegura a unidade íntima entre uma coisa e outra. Para a consciência comum da práxis tem de ser abandonada e superada para que o homem possa transformar, isto é, revolucionariamente, a realidade.

Para Frigotto (2000), a opção pelo enfoque teórico marxista parte da necessidade de conhecer a realidade para transformá-la. Para o autor trata-se do caráter radical ao conhecimento histórico na proposição de rupturas, pois

Filosofia e Educação [RFE] - volume 8, número 3 - Campinas, SP

Outubro de 2016-Janeiro de 2017 - ISSN 1984-9605 - p. 13-32 
“o embate teórico revela que há teorias que explicitam e revelam a realidade de forma mais completa, ainda que relativa, e outras que são mais parciais ou até obnubilam a realidade dos fatos." (p.81).Ainda de acordo com Frigotto (2000), o caminho lógico é feito pelo movimentar do pensamento, que significa refletir sobre a realidade partindo do empírico (a realidade dada, o real aparente, o objeto assim como ele se apresenta à primeira vista) e, por meio de abstrações (elaborações do pensamento, reflexões, teoria), para se chegar ao concreto: compreensão mais elaborada do que há de essencial no objeto, objeto síntese de múltiplas determinações.

Para Netto (2011), as determinações são traços reais, ou seja, constituem a expressão, a efetividade e o movimento do ser social e a forma de ser deste. A pesquisa, na ótica de Marx, é a busca das determinações. São operações pelo processo de saturação de determinações.

Seguindo a linha teórica e metodológica Marxiana, é preciso saber que o real é extremamente complexo e está em constante movimento dialético, ou seja, sofre transformações em consonância com as ações humanas. De acordo com Netto (2011), a razão nesse movimento deve apanhar suas riquezas estrutural e dinâmica, mas quando se chega ao concreto, tem que se retomar o caminho por aproximações sucessivas, na tentativa de realizar uma análise ampla das contradições e das mediações inseridas nas totalidades do objeto.

Relacionando com a questão da utilização de fontes de pesquisa, de acordo com Netto (2011), no caso de uma pesquisa de caráter Marxiano, a fonte pode ser documental. No entanto, é necessário operar com a confrontação entre as fontes históricas e os fatos concretos. Para Marx todo texto expressa a realidade, inclusive os documentos. O pesquisador deve ter um acervo categorial que lhe permita o movimento da abstração para captar e analisar os fatos expressados nos documentos. É fundamental a busca por uma análise coerente dos documentos, sem negligenciar que eles refletem 
contextos estrutural e conjuntural. Contudo, simultaneamente, deve se buscar o desenvolvimento histórico, a diacronia, ou seja, um corte horizontal no objeto.

De acordo com Vázquez (2007), não basta analisar nossas organizações sociais mediante cortes sincrônicos, mas sim preocupar-se em entender como se rompe sua relativa estabilidade, e quais são a gêneses e os processos evolutivos de uma nova ordem, isto é, entender a história ou, se assim se prefere, a diacronia. Já de acordo com Gamboa (2010), a preocupação diacrônica é radicalmente marcante nas pesquisas dialéticas, tendo na ação uma das principais categorias epistemológicas. Todavia, nos enfoques dialéticos, a história refere-se à compreensão da dinâmica interna dos fenômenos, que se torna foco prioritário das buscas.

Ressalta-se que a análisede documentos é considerada como um meio viável de possibilitar a abstração de determinações da realidade, na busca do concreto pensado, em referência aos fenômenos e contextos em que o objeto de estudo está envolvido. A análise das fontes primárias possibilitam abstrações e aproximações sucessivas com a produção bibliográfica. Nesta relação, tem-se como consequência o enriquecimento das análises.

Ainda sobre as análises documentais, de acordo com Chizzotti (2010), a pesquisa documental se insere de forma intrínseca no processo da pesquisa e corresponde, não apenas na análise dos documentos, mas, também, na importância das informações documentadas, na escolha dos documentos para a realização do estudo relacionado especificamente ao problema, na busca de onde encontrá-los, além do cuidado de como utilizá-los, a partir dos objetivos da pesquisa. No que se refere à pesquisa bibliográfica, trata-se da recorrente leitura, abstração, análises sistemáticas, fichamentos, sínteses sobre a literatura já publicada sobre o objeto de estudo e as categorias de análise. A pesquisa bibliográfica é fundamental para a escolha e 
identificação do objeto, elaboração do plano de trabalho, identificação das fontes, assim como para a análise dos dados.

Em relação à pesquisa de campo, é utilizada para conseguir informações acerca do objeto pesquisado, em atenção ao fato de que o observador desempenha função investigativa para conseguir coletar os dados. Esta, por sua vez, pode ser realizada por meio da técnica da entrevista semiestruturada, que, na visão de Minayo (2010, p. 261), é a técnica que "combina perguntas fechadas e abertas, em que o entrevistado tem a possibilidade de discorrer sobre o tema em questão sem se prender à indagação formulada".

As pesquisas "documental e de campo", atreladas à revisão bibliográfica, permitem a construção teórica sobre o objeto de pesquisa. É indispensável para o conhecimento e construção teórica, o conhecimento minucioso dos elementos empíricos. Para este processo de abstração, as ideias de Netto (2011) são adequadas, uma vez que, o pensamento localiza, detecta, interpreta esses processos, os quais são conectados a outros processos. Esses outros processos também são fatos, também se expressam empiricamente. Então, o pensamento volta à empiria para abstraí-la novamente. Ao voltar à abstração de outro fato interligado, a pesquisa retorna à forma empírica. Contudo, apesar da abstração e apesar do movimento teórico, os fatos continuam lá. Todavia, o fato já não é tido pelo pensamento como do ponto de partida.

De acordo com Silvio Gamboa (2009), a compreensão das técnicas de pesquisa está no método, pois é o processo da pesquisa que qualifica as técnicas e os instrumentos. Considera-se que as pesquisas são influenciadas pelas "condições históricas de sua produção (inter-relações materiais, culturais, sociais e políticas)" (GAMBOA, 2009, p. 73). De acordo com o autor, sobre os pressupostos gnosiológicos, estes "correspondem às maneiras de tratar o real, o abstrato e o concreto no processo da pesquisa

Filosofia e Educação [RFE] - volume 8, número 3 - Campinas, SP

Outubro de 2016-Janeiro de 2017 - ISSN 1984-9605 - p. 13-32 
científica" (p. 71). Para o autor, existem diversos modos de relacionar o sujeito e o objeto da pesquisa, no que se refere ao processo de pesquisa e de sistematização do conhecimento.

Em relação aos pressupostos ontológicos, Gamboa (2009, p. 71) versa que são "concepções do homem, da sociedade, da história, da educação e da realidade, que se articulam na visão de mundo implícita em toda produção científica". É com essas possibilidades que se esclarece a visão de mundo e se aproxima da opção teórico-metodológica. Como já mencionado, os pressupostos Marxianos orientam o processo de enriquecimento intelectivo a fazer os nexos necessários no processo da pesquisa, no qual será buscado apreender a essência, ou seja, a estrutura e a dinâmica do objeto.

Segundo Gramsci (2011), o marxismo é a filosofia da práxis. Para o autor a filosofia almeja para os seres humanos uma concepção de vida superior, vista esta que, segundo o autor, provoca com frequência a valorização maior do elemento prático. A superação do estágio do senso comum é amplamente necessária, assim, Gramsci (2011) menciona que se trata da passagem de uma concepção mecanicista para uma concepção ativista, que se aproxima da compreensão da unidade entre teoria e prática. Posteriormente, chega-se à compreensão crítica de si mesmo, uma elaboração superior da própria concepção do real.

De acordo com Marx (2008), o conhecimento mais difundido em uma época não é necessariamente verdadeiro, pois as determinações do capital incidem na forma de pensar e na construção do senso comum. É por isso que Marx recorre às análises históricas e dialéticas em seu meio de fazer ciência.

A análise Marxiana parte do real, do objeto concreto, da intuição sobre este e da representação deste, pois o concreto só aparece no pensamento como processo de sínteses. Portanto, é tarefa do pesquisador e do educador 
ajudar a elaborar e difundir uma concepção do real superior e atrelar isso à luta por outra sociedade.

Löwy (1998) e Frigotto (2000) veem no método marxista muito mais que um método de interpretação da realidade, os veem como uma ética da solidariedade, num projeto revolucionário e numa utopia sobre o futuro, cumprindo seu papel unificador, que demarca uma postura de concepção de mundo, enquanto método de apreensão radical da realidade e enquanto práxis que possibilita a busca de transformação e de novas sínteses no âmbito do conhecimento da realidade histórica.

De acordo com Vázquez (2007), em sua acepção revolucionária, a práxis é uma prática que aspira melhorar radicalmente uma sociedade, em termos éticos, com o projeto socialista. O marxismo supera o ponto de vista da consciência comum (na qual a essência se manifesta de maneira direta e imediata em sua aparência de forma mistificada) para o seu sentido verdadeiro como atividade real, objetiva, material do homem que só é homem como ser social prático.

De acordo com Netto (2011), a importância de trabalhar a pesquisa no caminho da incorporação crítica, seja de autores marxistas ou de outra corrente teórica. Primeiro, é necessário analisar as questões que os autores põem: se há questões legítimas em suas questões, sem incorporar, necessariamente, suas respostas. Isso implica um diálogo com pensadores, mas, ao mesmo tempo, uma crítica constante às questões e às respostas deles.

Contudo, para Marx e Engels (2007), todas as formas de relações humanas são condicionadas pela produção dos bens materiais. O trabalho é atividade vital, sem o qual não se produz vida humana. É por meio dele que o ser humano transforma a natureza em cultura e possibilita a construção dos meios de garantia da existência humana e a produção de bens materiais. O capitalismo exacerba a alienação do homem ao explorar o trabalho a 
níveis infindáveis, se utilizando também de ideologias, inclusive científicas, para moldar e acomodar as pessoas em meio a tal estranhamento.

Por outro lado, então, é fundamental e inadiável adotar novas sínteses em patamares teórico-práticos mais elevados, portanto a defesa do MHD enquanto epistemologia e o socialismo enquanto projeto histórico de sociedade, elaborar e difundir uma concepção do real superior e atrelar isso à luta por outra sociedade, a socialista.

\section{Considerações finais}

Nestas breves considerações finais, ressaltamos que é importante interpretar o mundo, mas é fundamental transformá-lo. Nesse sentido, analisamos a importância de reatar os vínculos entre a teoria do conhecimento e a epistemologia. Defendemos a tese de que com o MHD a dialética e a práxis passam a serem categorias centrais e à luz desta que se devem abordar os problemas do conhecimento, da história, da sociedade e da própria realidade e, inclusive, dos fenômenos da educação física. Desta forma, a possibilidade de superação do quadro epistemológico atual da área reside na reversão do circuito do conhecimento, com base no MHD e no paradigma da cultura corporal.

Ressaltamos, de acordo com Gamboa (2010), que a epistemologia da EF se constitui numa necessidade na medida em que a pesquisa científica se torna o eixo essencial para a consolidação da área como campo epistemológico. Todavia, isto não seria suficiente, ainda para o autor é necessário que a discussão sobre a relação teoria-prática seja central e pressuponha a dialética e a práxis como categorias centrais, tendo como base o paradigma da cultura corporal, radicalizando a relação dialética entre teoria e prática.

Analisamos que com a contribuição da epistemologia, a pesquisa científica ganha em qualidade, uma vez que a comunidade científica 
alimenta-se da reflexão crítica sobre os processos, os resultados, e as orientações da produção. No entanto, ressaltamos de acordo com Albuquerque e Taffarel (2010) que é fundamental tratarmos das categorias modo de produção capitalista, imperialismo, concentração da produção e monopolização, capital financeiro, modo de vida e organização do trabalho de produção da ciência.

Por fim, é necessário, portanto, o compromisso com uma prática éticopolítica, considerando a política como práxis, a qual se constitui de sujeitos, os quais se educam para socializar e dirigir o mundo. Ainda, é fundamental e inadiável adotar novas sínteses em patamares teórico-práticos mais elevados, portanto a defesa do materialismo histórico dialético enquanto epistemologia e o socialismo enquanto projeto histórico de sociedade, elaborando e difundindo uma concepção do real superior e atrelar isso à luta por outra sociedade.

\section{Referências}

ALBUQUERQUE, J.; TAFFAREL, C. N. Z. Epistemologias e teorias do conbecimento em educação e educação física: reações aos pós-modernismos. Filosofia e Educação (Online), ISSN 1984-9605 - Revista Digital do Paideia. Volume 2, Número 2, Outubro de 2010.

CHIZZOTTI, A. Pesquisa em ciências humanas e sociais. 11. ed. São Paulo: Cortez, 2010. 166 p.

CURY, C. R. J. Educação e contradição: elementos metodológicos para uma teoria crítica do fenômeno educativo. 7.ed. São Paulo: Cortez, 2000. 134 p.

FRIGOTTO, G. O enfoque da dialética materialista histórica na pesquisa educacional. In: FAZENDA, I (org.) Metodologia da Pesquisa Educacional. 6. ed. São Paulo: Cortez, 2000. 174 p.

GAMBOA, S. S. Quantidade-Qualidade: para além de um dualismo técnico e de uma dicotomia epistemológica. In: SANTOS FILHO, José Camilo dos; 
GAMBOA, Sílvio Sánchez (Org.). Pesquisa educacional: quantidade-qualidade. São Paulo: Cortez, 2009. p. 84-107

GAMBOA, S. S. Epistemologia da Educação Física: as inter-relações necessárias. 2. ed. rev. e ampl. Maceió: EDUFAL, 2010. 215 p.

GRAMSCI, A. Cadernos do cárcere v. 1. 5.ed. Edição e tradução Carlos Nelson Coutinho; coedição Luiz Sérgio Henriques e Marco Aurélio Nogueira. Rio de Janeiro: Civilização Brasileira, 2011. 495 p.

GIL, A. C. Como elaborar projetos de pesquisa. 4.ed. São Paulo: Atlas, 2002. 175 p.

LOWY, M. Ideologias e ciência social: elementos para uma análise marxista. 20.ed.

São Paulo: Cortez, 2015. 143 p.

MARX, K. Contribuição à crítica da economia política. 2.ed. São Paulo: Expressão Popular, 2008. 288 p.

MARX, K.; ENGELS, F. A ideologia alemã. Tradução de Rubens Enderle, Nélio Schneide e Luciano Cavini Martorano. São Paulo: Boitempo, 2007. 614 p.

MINAYO, M. C. O desafio do conhecimento: pesquisa qualitativa em saúde. 12.ed. São Paulo: Hucitec, 2010. 407 p.

NETTO, J. P. Introdução ao método de Marx. 1.ed. São Paulo: Expressão Popular. $64 \mathrm{p}$.

SÁ, K. O. de; SILVA, I. C; SANTOS, G. T. dos. Análise da produção do conbecimento pesquisa em rede com base no materialismo bistórico-dialético. Filosofia e Educação (Online), ISSN 1984-9605 - Volume 5, Número 2, Outubro de 2013.

Taffarel, C. N. Z. Epistemologia da Educação Física: as inter-relacoões necessárias/In: Sílvio Ancízar Sanchez Gamboa. 2. ed. rev. e ampl. Maceió: EDUFAL, 2010. $215 \mathrm{p}$.

VÁZQUEZ, Adolfo Sanchez. Filosofia da Práxis. 1.ed. São Paulo: CLACSO Expressão Popular, 2007. 440 p 